\title{
Teoria Historiográfica* diálogo entre Tradição e Inovação
}

\author{
Historiographic theory \\ a dialogue between tradition and innovation
}

\author{
Astor ANTÔNIO DIEHL \\ Doutor em Teoria, Metodologia e Didática da História \\ pela Ruhr-Universität Bochum, Alemanha \\ Professor do Curso Graduação de História e do Mestrado \\ em Educação da Universidade de Passo Fundo/RS \\ cph@upf.br
}

\begin{abstract}
RESUMO Objetiva-se discutir algumas perspectivas de estudos nos campos das teorias da história e da historiografia, tomando como eixo os pressupostos para o diálogo entre tradição historiográfica e o conjunto de inovações verificadas nos estudos históricos atuais. A partir desse objetivo estabelecemos dois aspectos para a estrutura do texto: o primeiro envolve a possibilidade da inserção de noções como a dos desejos e das subjetividades para a dimensão teórica e historiográfica; o segundo aspecto discute os sentidos dessa inovação, entendida a partir da noção cultura historiográfica e da plausibilidade do conhecimento histórico.
\end{abstract}

Palavras-chave Teoria da História, cultura historiográfica, plausibilidade científica

ABSTRACT The article intends to discuss a few study perspectives in the field of theory of history and historiography, departing from the premises that inform the dialogue between historiographic tradition and the innovations

* Artigo recebido em 23/02/2006. Autor convidado. 
that affect today's historical studies. The text has a two-fold structure: the first involves the possibility of manifesting desires and subjectivities in the theoretical and historiographic dimension, while the second discusses such innovation, understood from the point of view of "historiographic culture" and of the plausibility of historical knowledge.

Key words theory of History, historiographic culture, scientific plausability

\section{Diagnóstico inicial}

Em recente obra, Catherine Gallagher e Stephen Greenblatt propõem o "desafio de tentar esclarecer até que ponto o novo historicismo mudou o campo da história literária e como isso poderia ser traduzido em uma teoria das representações"1 tendo como pano de fundo o estudo de anedotas, doutrina eucarística da Idade Média tardia e o Renascimento, o materialismo, pão, batatas e mortos. Num primeiro momento, isso poderia parecer uma combinação bastante explosiva.

O objetivo desse texto é discutir pressupostos de estudos para a área de historiografia e cultura historiográfica, compreendendo-o a partir do estabelecimento do diálogo entre tradição historiográfica e as perspectivas inovadoras atuais. A noção cultura historiográfica envolve, necessariamente, as dimensões constitutivas dos seus próprios parâmetros a partir de problemáticas do tempo presente. Assim sendo, nosso debate se alinha com questionamentos que estão situados em dois vetores.

O primeiro vetor estabelece elementos vinculados aos aspectos vindos de três pensadores da história: a pergunta "o que estou fazendo quando escrevo história?", formulada por Michel de Certeau, ${ }^{2}$ a interrogação de Jean Chesneaux sobre "se devemos fazer tábua rasa do passado?" ${ }^{3}$ e, finalmente, Remo Bodei faz a pergunta bastante enfática: "se a história tem um sentido?"4

O segundo vetor apresenta a própria dinâmica das mudanças provocadas pela propalada crise da razão histórica, agregada e observadas durante os últimos anos nos estudo historiográfico.

Com esta base de estudos é possível, em tese, afirmar que estamos assistindo uma espécie de revanche do acontecimento sobre a estrutura,

\footnotetext{
GALLACHER, Catherine; GREENBLATT, Stephen. A prática do novo historicismo. Bauru: Edusc, 2005 CERTEAU, Michel de. A escrita da história. Rio de Janeiro: Forense, 1982

CHESNEAUX, Jean. Devemos fazer tábua rasa do passado? São Paulo: Ática, 1995

BODEI, Remo. A história tem um sentido? Bauru: EDUSC, 2001. A contrapartida desses questionamentos pode ser acompanhada no esforço de DOSSE, François. A história à prova do tempo: da história em migalhas ao resgate do sentido. São Paulo: ed. da UNESP, 2001 e de RÜEN, Jörn. Perda de sentido e construção de sentido no pensamento histórico na virada do milênio. In: Rev. História: debates e tendências. Passo Fundo: v. 2, n. 1, p. 9-22, dez de 2001.
} 
do local-regional sobre o nacional por um lado. Por outro, as abordagens historiográficas dão ênfase extraordinária às formulações discursivas do passado, numa espécie de ciência do texto. Esta última é uma marca da cultura contemporânea muito bem caracterizada pela noção Spätzeit. ${ }^{5}$

No entanto, não basta somente a consciência daquilo que está mudando e que fora condenado no passado como sendo representações historiográficas tradicionais. Certamente apenas este aspecto não nos levaria além da percepção polarizada. O historiador precisaria desenvolver outros instrumentos metodológicos para poder dar sentido aos fragmentos e buscar um novo horizonte de expectativas à sua representação do passado. Entretanto, tal tendência mostra a larga recepção, entre os historiadores, de questões vinculadas às estruturas narrativas e de uma aproximação mais íntima entre história e literatura. Apesar desse "avanço" estratégico das formas narrativas, o historiador continua tropeçando em destroços do passado que irrompem na cena contemporânea. A diferença neste momento está no fato do historiador não poder mais usar modelos teóricos de seleção e classificação de restos e tradições do passado como fazia anteriormente sem, pelo menos, questionar seu grau de plausibilidade. A heterogeneidade temporal, política e cultural impede-nos de fazer tábua rasa em termos de sentidos e significados. Tal heterogeneidade revela um espaço cultural contemporâneo saturado de diferenças. ${ }^{6}$

Esta situação do espaço cultural atual gera, por sua vez, uma reação. Por esta reação entende-se a saturação como um obstáculo à originalidade e a inovação ou mesmo a possibilidade de produção de conhecimentos. Tudo já teria sido dito, feito e narrado. Restaria então, uma espécie de saída estratégica em direção ao mundo primitivo, situado em algum momento antes da modernidade. Um desejo de busca da comunidade, do pequeno, do micro e, porque não, de recolocar o sujeito ético-moral no centro do palco como a força motriz do sentido. A semiotização atual retirou o próprio sentido daquilo que poderíamos chamar de clandestinidade. ${ }^{7} \mathrm{E}$ nesse aspecto, em termos gerais, vale a política do plano da reconstituição dos sentidos lá onde existem basicamente intimidades.

Estaríamos nos encaminhando para uma ciência do texto sobre as experiências simbólicas em detrimento daquelas vinculadas na relação explicativa do homem-natureza-trabalho. Assim, o contexto historiográfico

5 Noção desenvolvida, na perspectiva de uma modernidade tardia, por MOSER, Walter. Spätzeit. In: MIRANDA, Wander (org). Narrativas da modernidade. Belo Horizonte: Autêntica, 1999. p. 33-54. O anúncio do retorno à narrativa também está em HOBSBAWM, Eric. Sobre a história. São Paulo: Cia das Letras, 1998. p. 201-206.

6 Esta discussão leva a uma infinidade de situações que não teremos chances de debater aqui, no entanto sugerimos os seguintes textos: SEMPRINI, Andrea. Multiculturalismo. Bauru: Edusc, 1999; CUCHE, Denys. A noção de cultura nas ciências sociais. Bauru: Edusc, 1999 e SCHNITMAN, Dora Fried (org.). Novos paradigmas, cultura e subjetividade. Porto Alegre: Artes Médicas, 1996; MATHEWS, Gordon. Cultura global e identidade individual. Bauru: Edusc, 2002 e KELLNER, Douglas. A cultura da mídia. Bauru: Edusc, 2001.

7 Para este aspecto ver a discussão feira por HUTCHEON, Linda. Poética do pós-modernismo: história, teoria, ficção. Rio de Janeiro: Imago Ed., 1991, especialmente a segunda parte, p.141-290. 
atual pode perfeitamente revelar as estratégias para a formação de desejos simbólicos nos campos social e cultural. Essa tendência mostra-nos que a compreensão do cultural seria entendida apenas como a política do plano estrutural concluído e das estratégias que somente reconheciam o visível à priori estabelecido pelos conceitos e teorias. ${ }^{8}$

De outra forma, a situação do espaço cultural também pode mostrar que a mesma saturação seja percebida com a condição sine qua non da produção de novos sentidos. Aquilo que antes fora varrido para debaixo do tapete tornar-se-ia agora a matéria-prima das novas significações e sentidos. Nessa orientação, o custo da modernização seria agora visto não mais como obstáculo, mas como recurso para sua reutilização através dos esforços da narrativa, da meta ficção ou da intertextualidade. ${ }^{9}$

Configura-se, portanto, um terreno fértil e promissor para o avanço do debate das estruturas narrativas pós-modernas num modo de produção das subjetividades ${ }^{10}$, através de uma espécie de ciência do texto como referimos acima.

Recentemente, Hans-Ulrich Wehler caracterizou as tendências da nova história cultural pela sua abstinência política e pelo seu relativismo. Seria como se fôssemos nadar com a onda cultural, quando nela estariam sendo enfocadas noções, tais como: a diferença e a desconstrução, o discurso e a identidade. Seriam trabalhos que se ornamentam com a análise do discurso, distanciando-se da disciplina metódica e da ciência histórica. ${ }^{11}$

A recombinação de temporalidades diferentes numa mesma narrativa não é mais vista como uma deformação anacrônica ou mesmo sinônimo de desordem, mas de constituição de um sistema lógico que trabalha com sentidos pré-constituídos. Pela dinâmica interna do sistema e pelos seus enunciados, a narrativa e a estética assumem o papel principal. O conteúdo histórico em essência torna-se periférico, porém sobre o qual ainda se narra e se estiliza. As múltiplas recombinações de temporalidades possíveis no sistema levam a implodir as polarizações de posições tão caras ao pensamento dialético.

Por vezes, essas tendências são duramente criticadas como sendo mera reciclagem, pastiche ou mesmo canibalismo cultural. Todo esse processo estaria levando ao esgotamento cultural, a falta de originalidade e a ausência de crítica. ${ }^{12}$ Entretanto, não podemos fechar os olhos para o ambiente atual

8 DIEHL, Astor Antônio. A cultura historiográfica nos anos 80: mudança estrutural na matriz historiográfica brasileira (IV). Porto Alegre: Evangraf, 1993. Especialmente o capítulo 4, denominado O exemplo de Walter Benjamin, p. 95-117.

9 Desenvolvemos esse aspecto no livro Vinho velho em pipa nova. Passo Fundo: Ediupf, 1997.

10 O recurso deste processo encontra-se na obra de GUMBRECHT, Hans Ulrich. Modernização dos sentidos. São Paulo: editora 34, 1998.

11 Ver WEHLER, Hans-Ulrich. Historisches Denken am Ende des 20. Jahrhunderts. Göttingen: Wallstein, 2001 .p. 79-86.

12 Ver SOKOL, Alan e BRICMONT, Jean. Imposturas intelectuais. O abuso da ciência pelos filósofos pós-modernos. Rio de Janeiro: Record, 1999 
na cultura historiográfica brasileira, que é caracterizado pela incessante crítica à razão histórica. ${ }^{13}$ Assim, dessa crítica, uma primeira orientação é aquela que procura uma solução para a crise no (ir)racionalismo carismático, no jogo, na subjetividade e no estético. ${ }^{14}$

Uma segunda orientação rejeita esta perspectiva, mas não deixa de se refugiar ao antimodernismo comunitário, desta vez supostamente identificada na conotação política de emancipação. ${ }^{15}$ Percebe-se que a questão se direciona no sentido da junção de forças antagônicas (aparentemente), resultando daí o gosto pelas diferentes temporalidades simultâneas. Portanto, deixou-se de perseguir as explicações racionais sobre as razões estruturais e conjunturais de determinados contextos históricos em nome de possíveis orientações 'pós-modernas'. ${ }^{16}$

Por que isso ocorre? Gostaria de levantar algumas suspeitas para essa situação.

Primeiramente, vivemos num clima deixado pelas frustrações intelectuais e sociais, pois as revoluções otimistas, aquelas que projetavam a redenção no futuro, não aconteceram nos moldes teorizados. Esse é um dos fatores que deram origem ao pessimismo em relação ao futuro e a própria possibilidade de mudança social. Isso, por sua vez, gera uma crise de critérios científico-racionais sobre os quais tais paradigmas estavam assentados. Convivemos assim com o clima da suspeita e a (in)transparência teórica e, em alguns casos, com a demissão da razão.

Em segundo lugar, o clima é de fragmentação da ordem estabelecida. Essa fragmentação é uma das conseqüências dos processos de modernização que explodem as tradições culturais e, nesse caso, também as tradições historiográficas. Berman diria: "tudo que é sólido desmancha no ar". ${ }^{17}$ Esse contexto poderia nos deixa numa atmosfera de insegurança, pois os antigos critérios de validade já não cobrem mais a realidade e desconfiamos profundamente dos novos. ${ }^{18}$ Os processos de modernização geram custos sociais e culturais, apresentados, sobretudo no mundo acadêmico, através da fragmentação dos estudos históricos. Portanto, já que

13 Este aspecto não é um privilégio da história e dos historiadores. É um debate que abrange todas as áreas do conhecimento. HORGAN, John. O fim da ciência. Uma discussão sobre os limites do conhecimento científico. São Paulo: Cia das Letras, 1998.

14 Ver, por exemplo, recente texto de ALBUQUERQUE JÚNIOR, Durval Muniz de. A história em jogo: a atuação de Michel Foucault no campo da historiografia. In: Anos 90. Revista do Programa de Pós-Graduação em História. UFRGS, Porto Alegre, v.11, n⿳019/20, p.79-100. jan./dez.2004

15 Discutimos estes dois aspectos a partir de Max Weber. Ver DIEHL, Astor Antônio. Max Weber e a história. Passo Fundo: Ediupf, 1996.

16 Recentemente foram feitos dois inventários sobre as tendências e campos do debate no campo da história. REIS José Carlos. História \& Teoria: historicismo, modernidade, temporalidade e verdade Rio de Janeiro: FGV, 2003 e BARROS, José D'Assunção. O campo da história: especialidades e abordagens. Petrópolis: Editora Vozes, 2004.

17 BERMAN, M. Tudo que é sólido se desmancha no ar. São Paulo: Cia das Letras, 1988

18 Ver SANTOS, Boaventura de Souza. Um discurso sobre as ciências. $11^{\text {a }}$ ed. Porto: Edições Afrontamento, 1999. Pode-se agregar a leitura dos antropólogos entre outros. Ver então KUPER, Adam. Cultura: a visão dos antropólogos. Bauru: Edusc, 2002. 
a sociedade e os sujeitos estão fragmentados (fracionados e hostis entre si), a tendência básica é um retorno ao indivíduo. Neste sentido existe uma forte perspectiva de individualização das perspectivas de reconstituição do futuro no passado.

Pois bem, os dois aspectos que apontamos, geram alguns dilemas estruturais e culturais que avançam sobre nossas posturas acadêmicas e profissionais. Ao nível acadêmico apresentam-se dois aspectos: o discurso da conciliação acadêmico-social e a crítica conformista da historiografia inserida na nova história. ${ }^{19}$ Já no nível dos resultados das pesquisas e temáticas abordadas temos uma espécie de enclausuramento do indivíduo ou de pequenos grupos em si mesmos. Existe nesta perspectiva uma fuga orientada que vai da esfera pública para o privado e para a esfera das soluções hedonistas e imediatas.

Sem dúvida, o momento é dos cotidianos íntimos da vida, das experiências do sujeito, a vez é das bruxas e das feiticeiras, dos loucos, dos vadios, dos homossexuais, dos gestos significativos tais como o medo, o desejo, a angústia etc. A vez é daquilo que denominamos de compensações dos custos resultantes dos processos de modernização ${ }^{20}$ otimistas lineares, daquilo que historicamente fora banido pela ciência formal. Parece que procuramos no passado àqueles gestos significativos que compensam a falta de critérios transparentes no presente, preenchendo assim o vácuo. Radicalizando poder-se-ia dizer: romantizamos, idealizamos aspectos do passado num esforço quase saudosista para restabelecer a ordem perdida. ${ }^{21}$

Essa última orientação, por certo, não é ingênua e não está longe de justificar e legitimar o ressurgimento de mitos do século XIX, tais como: da nação, do étnico, da personalidade, da geopolítica e da tradição cultural, este último como elemento autônomo. Isso traz de volta a estratégia das soluções localizadas e carismáticas.

Com essa perspectiva temática surgem alguns aspectos que merecem ser apontados: a) a analogia entre a reconstrução da biografia e a interpretação crítica através dela de estruturas simbólicas em geral; b) a ciência não desempenharia mais seu papel de motor do pensamento, por que esta função já está ocupada pela política; c) a história como disciplina com plausibilidade científica não teria mais a função de propor identidades, pois a historiografia seria o resultado de racionalizações metodológicas e a identidade se forma e cumpre funções através de elementos passionais e afetivos.

\footnotetext{
19 Ver novamente a crítica contundente de WEHLER, Hans-Ulrich. Op. cit.

20 Sobre os custos ver GIDDENS, Anthony. As conseqüências da modernidade. $2^{a}$ ed. São Paulo: Ed. Da UNESP, 1991. Também WARNIER, Jean-Pierre. A mundialização da cultura. Bauru: Edusc, 2000.

21 Num outro sentido ver LÖWY, Michel. Romantismo e messianismo. São Paulo: Perspectiva: Edusp, 1990.
} 
Nesse sentido, o lastro de conteúdos do passado, que alavanca a possibilidade de identificações, passa a ser percebido tal como deveria ter sido. Entretanto, nós já entendemos que esse passado nunca existiu, a não ser na imaginação ou na afetividade do sujeito da experiência. A outra leitura desse passado é aquela que remete o sentido metodológico do como é possível de ser reconstituído.

Nessa orientação, não entendemos tais conseqüências da crise como sendo negativas ou sem sentido para a história-disciplina, mas sim como possibilidade de problematizarmos o passado no sentido de reconstituir idéias de futuro que se tinha no passado e, sobretudo, creditarmos argumentos para uma cultura da mudança a partir da proposição de alguns temas.

\section{Significado ampliado e importância da cultura histórica}

Se estiver correta a afirmativa que os desejos humanos foram quase sempre banidos dos debates em disciplinas humano-sociais com fortes características científicas, que não seja a psicologia e psicanálise, então o seu lugar nas ciências humanas também parece estar sujeito às inovações no que diz as normas de sua plausibilidade em termos de conhecimentos racionalizados e de discursos.

Por outro lado, devemos ter clareza sobre o fato de que o acesso aos conteúdos dos desejos e da subjetividade, como fontes de conhecimentos do passado, é dificultado muitas vezes pela própria normatização técnica da pesquisa, feita por vezes ainda dentro de cânones científicos ainda bastante tradicionais, que, por sua vez, deixam a história intoxicada por uma exagerada racionalidade instrumental. ${ }^{22}$

Tais características exerceram grande influência sobre o que seria 'proibido' ou escamoteado através da poética do possível em termos de questionamentos e, conseqüentemente, também como possibilidades de respostas plausíveis para os fenômenos que estariam fora da vocação da ciência moderna. Nessa perspectiva, o tempo presente é agora apresentado de forma mais densa de experiências e temporalidades. Por outro lado, são exatamente estas proibições e as insuficientes respostas que poderão servir de estímulos para o exercício de reconstituição do passado através dessas mesmas fissuras culturais.

Talvez esteja exatamente aí o ponto nevrálgico para discutirmos os desejos e a subjetividade bem como os seus desdobramentos para os sentidos e significados da história e da cultura historiográfica. Esta postura é parte integrante da perspectiva que debate sobre os deslocamentos do

22 Fizemos uma tentativa para compreender a forte tendência da normatização metodológica e técnica na pesquisa histórica no livro Do método histórico. Passo Fundo: Ediupf, 1996 (2ª edição 2001). 
centro e sua dissolução na composição dos horizontes das representações históricas.

Nessa proposta está a discussão de alguns pontos que podem quebrar a abstração sistêmica da historiografia de dentro - a partir do centro — para então tentarmos mostrar a própria fragilidade do domínio das verdades consolidadas através da ciência moderna e esta, por sua vez, conseguir ser um aval de transparência cultural.

Com esta perspectiva quer-se afirmar que os desejos e a subjetividade, assim como o sofrimento e os sonhos podem se tornar algo específico para as explicações e as compreensões do estranho, porém do fascinante mundo dos homens. Aliás, quando os homens do passado chegarão até nós do tempo presente?

Já foi discutido em outra oportunidade sobre o fascínio da eco história humana, realizada a partir do debate entre modernidade e pós-modernidade, mas vale a pena perguntar novamente ${ }^{23}$ : o que nos une como seres da mesma espécie senão a experiência da vida? Justamente, esta fascinante experiência da vida que nos repara e nos torna tão diferentes uns dos outros recheados de alteridade.

Em contrapartida, a discussão sobre os desejos e subjetividade se orienta sobre o processo de constituição do social e do campo da privacidade humana. Isso significa conectar o desejo a uma razão prática comum e dela poder resultar, em termos metodológicos, a reconstituição de perspectivas orientadoras soterradas pela razão instrumental e científica. ${ }^{24}$

Portanto, a questão de fundo não gira em torno apenas em trazer o desejo para o discurso de validade, mas procurar mostrar e evidenciar que sua influência vai muito além daquilo que os discursos instrumentais conseguiam afirmar sobre a (in)transparência do desejo em termos sociais e culturais. Feita esta demarcação inicial, queremos expor agora alguns tópicos que ajudam na argumentação para justificar as possibilidades de compreensão da história e apresentar sua importância no debate proposto sobre o diálogo entre tradição e inovação.

O fascínio das grandes teorizações ainda não foi perdido no próprio caminho da razão no ocidente. Talvez pudéssemos dizer que se vive um tempo de provações e de purgação nas modernas filosofias da história. Se, por um lado, a responsabilidade pessoal é exaltada como um bem supremo, por outro, esta noção não parece dispensável na estruturação da complexa rede que envolve a economia das trocas culturais.

23 DIEHL, Astor Antônio. Vinho velho em pipa nova: o pós-moderno e o fim da história. Passo Fundo: Ediupf, 1997. 24 Conforme a discussão de TOULMIN, Stephen. Kritik der kollektiven Vernunft. Frankfurt: Suhrkamp, 1978. Os efeitos destas contradições estão em BOUDON, Raymond. Widersprüche sozialen Handelns. Darmstadt, Neuwied: Luchterhand, 1979. 
Talvez não tivesse havido até agora, na história da formação e consolidação do pensamento historiográfico moderno, um momento em que a questão do debate sobre os sentidos da história estivesse tão em evidência. São inúmeros artigos e livros que procuram considerar o quanto o conhecimento histórico teria a contribuir na formação de uma consciência esclarecedora tanto nas experiências individuais como nas coletivas.

Por outro lado e se eu não estiver muito equivocado, consigo perceber um momento de superação da fase de crítica pura e simples feita aos princípios e a história da modernidade. ${ }^{25} \mathrm{~A}$ poeira e a fumaça das escaramuças estão lentamente dando lugar e cedendo espaços para posturas mais dialógicas. Esta percepção é possível de ser apresentada a partir da constante busca de sentidos e significados das representações historiográficas e culturais no momento presente.

Talvez seja possível até mesmo falar de uma agenda positiva - com o perdão da expressão desgastada - para as ciências humanas através da atribuição de um sentido renovado, pois as ciências humanas, e especialmente a história, tiveram e tem a difícil tarefa de olhar para o passado sem perder a visão da complexidade do presente, bem como ainda ter a consciência que o presente amplia os horizontes e as perspectivas da compreensão do passado. ${ }^{26}$ É, exatamente, nesta via dupla que encontramos as possibilidades de constituição dos múltiplos sentidos do conhecimento histórico. ${ }^{27}$

Entretanto, não é possível pensar em (re)constituir sentidos sem levar em conta a pluralidade de perspectivas originárias da memória - sejam elas institucionais ou experiências exemplares de indivíduos ou grupos -e como sendo esta uma dimensão essencial da atividade de historiar. Aliás, são duas vias ou vertentes de sentidos que aqui se fazem presentes como necessários: as perspectivas que as pessoas tinham e têm de seu passado, incluindo as projeções de futuro nela contidas, e os sentidos que os historiadores atribuem àquelas perspectivas e pensamentos das pessoas de seus passados.

Portanto, desde já vale a pena lembrar o fato que a memória também tem a pretensão de ser fiel ao passado. Claro, que esta é uma pretensão, a qual não se sustenta, pois a revelação do passado através da memória defende de um testemunho. Sem entrar na discussão sobre a confiabilida-

25 Ver em GANDILLAC, Maurice de. Gêneses da modernidade. São Paulo: editora 34, 1995

26 Em termos do pensamento histórico, ver os ensaios de REIS, José Carlos. História \& teoria: historicismo, modernidade, temporalidade e verdade. Rio de Janeiro: FGV, 2003.

27 Recentemente alguns historiadores tomaram esta tarefa como pauta de discussão. Destaco três historiadores de diferentes posturas teóricas que colocaram o sentido do conhecimento histórico no centro de suas publicações: RÜSEN, Jörn. Perda de sentido e construção de sentido no pensamento histórico na virada do milênio. In: Revista Histórica: debates e tendências. Passo Fundo: v. 02, no 02, p. 9-22, dez. de 2001; FONTANA, Josep. História: análise do passado e projeto social. Bauru: Edusc, 1998; DOSSE, François. O império do sentido: a humanização das ciências humanas. Bauru: Edusc, 2003. 
de do testemunho, pode-se dizer de antemão que as imagens reveladas o passado e a conseqüente atribuição de sentidos são sempre precários. Torna-se assim importante não apenas o conteúdo que a memória pode revelar, mas, sobretudo, a forma de transmissão dos conteúdos da memória, a qual denominaremos de memória do temor ou memória negada. ${ }^{28}$ Percebe-se então que a partir da memória surgem duas perspectivas de sentidos sobre as possibilidades do passado em relação a nossa postura no tempo presente: a coerção e a libertação.

Cabe aqui formular a pergunta e orientar o debate sobre as possibilidades de constituição dos sentidos do conhecimento histórico. De forma explícita, ao meu ver, esta deveria ser, tecnicamente, uma das primeiras tarefas do rol de atividades dos historiadores tendo em vista as próprias características do mundo atual, o qual já não comporta mais análises do tipo reducionista. A compreensão do mundo contemporâneo exige de todos nós dimensões que vão além do fato de apenas referenciarmos os objetos de pesquisa no passado.

Esse ir além dos fatos traz consigo dimensões que precisam levar em consideração a pluralidade de perspectivas no diálogo constante nas demais áreas do conhecimento, fato que para o profissional da história nem sempre é tranqüilo. Esta constatação, por outro lado, facilmente poderá ser acusada como relativista. Mas, aqui queremos estruturar argumentos a favor da tese de que ter posições relativas às diversas possibilidades de reconstituição dos sentidos não deve significar de que estamos caindo no inconseqüente 'vale tudo'. ${ }^{29}$ Assumir uma posição particular não significa que queremos sujeitos puros, mundos ideais, estruturas perfeitas e assim por diante. Significa muito mais trabalharmos com ecossistemas - sujeitos, mundos, estruturas - correlacionados nas suas interfaces que, por sua vez, intercambiam experiências e assim mesmo possuem sentidos próprios. ${ }^{30}$

Hoje, a mera atividade científica já não nos consegue mais dar respostas satisfatórias a todos os problemas colocados na pauta, pois a própria história também está bastante frágil e inflacionada ante ao fato de ter que buscar resoluções para as tarefas epistemológicas intrínsecas a ela. Mesmo com esta perspectiva, não deveríamos subestimar os avanços alcançados pelas ciências de forma geral, mas ter clareza sobre o fato de que nós nas ciências humanas não estamos sozinhos nesta empreitada para buscar entender o sentido das próprias descobertas científicas. ${ }^{31}$

\footnotetext{
28 É possível, com certo cuidado, relacionar tais expressões com a idéia do desenvolvimento humana. Estas relações estão expostas no livro de PHILIPS, Frank. Psicanálise do desconhecido. São Paulo: editora 34, 1997.

29 Tentamos discutir esses aspectos em Teoria da história e cultura da mudança: os argonautas da subjetividade. Bauru: Edusc, 2006 (prelo), especialmente na primeira parte.

30 Conforme SOUZA, Ricardo Timm de. Sobre a construção do sentido. São Paulo: editora Perspectiva, 2003, especialmente no capítulo 1.

31 Para uma retrospectiva histórica do papel da ciência ver ANDERY, Maria Amália et al. Para compreender a ciência $12^{a}$ edição. Rio de Janeiro: Garamond; São Paulo: Educ, 2003.
} 
A disponibilidade de diversos novos métodos, das inovadoras técnicas de pesquisa, de fontes, de objetos, de configurações temporais e de linguagens múltiplas são constantes no métier do historiador, correspondendo elas às possibilidades das várias reconstituições do passado e de seus sentidos e não apenas um diálogo de surdos. ${ }^{32}$

Esta é uma das razões pela qual não precisamos temer a dimensão de crise do pensamento e das múltiplas práticas na historiografia atual, pois esta dimensão de crise acompanha todo o processo de constituição da história como disciplina.

Já em termos da produção de conhecimentos históricos é uma falácia a representação verdadeira da realidade. A história é apenas uma textura de representações do passado, pois, metodologicamente falando, a história não é constituída como se faz na ciência formal, onde temos um corpo de proposições gerais que expressam somente fatos descobertos. A história seria muito mais a possibilidades de construirmos uma espécie de arquitetura das idéias de futuro que se tinha no passado através intromissões no passado.

Atribuir e constituir sentido são também formas de mutilar quando não de destruir a realidade no seu contexto histórico-social. A realidade carrega em si o descompasso entre o tempo passado e a capacidade dela ser reconstituída. Esta fissura causa uma estranha abertura entre o cenário e os atores - entre o passado e os sujeitos. E é exatamente esta abertura o horizonte de sentidos que são os sons e as cores da possibilidade de mudança, pois carregam um amplo espectro de subjetividades e desejos. Aqui, irrompe uma temporalidade saturada com todas as suas características imersas. Poder-se-ia falar de aspectos clandestinos, como zonas de silêncio e de sombras. Seria o momento da construção de sentidos para além das estruturas estabelecidas. ${ }^{33}$

Com esse significado podemos então perguntar: a obra de um historiador é realmente um processo de criação ou, na verdade, seria uma re-criação com atribuição de sentidos ao passado? Por vezes, e para não dizer na maioria das vezes, esta re-criação do passado expressa também a tese do como gostaríamos que tivesse sido?

Há certas dificuldades peculiares a este tipo de empreendimento, algumas de origens metodológicas especialmente quando pretendíamos explicar as estruturas de pensamento no passado. Geralmente, tais concepções metodológicas acabavam por demonstrar que existe uma aplicação tanto geral como particular e que elas seriam capazes de proporcionar

32 Conforme postura de BURKE, Peter. História e teoria social. São Paulo: Editora Unesp, 2002, especialmente o debate entre teóricos e historiadores, p. 11-37.

33 Está evidente que isso não se faz apenas pela história escrita. Ver OLSON, David R. O mundo no papel. As implicações conceituais da leitura e da escrita. São Paulo: Ática, 1997. 
generalizações. No caso de trabalharmos com os sentidos da história, essa postura metodológica pode facilmente apresentar-se com características reducionistas e os resultados serem a própria legitimação de concepções firmadas a priori.

Pensamos, então, que os caminhos mais promissores sejam aqueles que envolvem não apenas a descrição dos fatos em si, mas aqueles que objetivem a compreensão, especialmente através da hermenêutica e da fenomenologia. Para tanto, não é desafiar de escolas históricas, as quais foram e são as sementes das teorias da história e elas estão em toda parte. ${ }^{34}$ Como elas também fazem o pano de fundo intelectual muito amplo, as suas contribuições estão enterradas numa verdadeira erudição dificilmente domináveis.

Os primeiros passos, para qualquer nova postura, compreendem, sem dúvida, a necessidade de estabelecer relações dialógicas para substanciar o tratamento do assunto em questão. Portanto, a idéia pode parecer inicialmente paradoxal, revelando-se nela as contradições de posturas teóricas. No entanto, a relação entre história e sentido é evidentemente algo que deve superar as polarizações. Pois ela envolve não apenas a simples catarse, mas as possibilidades de identificações com tradições culturais, com memórias, com qualidades sensoriais, com sentimentos objetivos e não objetivados, com experiências individuais e coletivas que dificilmente podem ser explicadas apenas pelas contradições, apesar delas serem o fluxo vital dos sentidos na história. Esta relação dá-se sob forma de trocas simbólicas, para usar uma expressão central apresentada por Pierre Bourdieu.

Até este momento consideramos a história quase que inteiramente a partir do que se poderia chamar de 'ponto de vista acadêmico', refletindoa como produção de conhecimentos de um autor, isto é, como algo que toma forma à medida que são articulas as representações narrativas do passado a partir de sistemas de referências. O que o historiador produz é uma expressão textual organizada a partir de pontos de vistas de interesses pelo conhecimento, de perspectivas de orientação teórica, de estratégias metodológicas e de estruturas narrativas.

Tudo isso visa de certa forma racionalizar o passado para que se chegue o mais próximo possível de uma 'objetividade' e, portanto, que esse conhecimento contenha funções sócio-culturais que extrapolem a subjetividade de quem a produz. Talvez poderíamos afirmar que, do ponto de vista do autor, o processo de produção do conhecimento se bastaria até este momento.

Portanto e para além do conhecimento propriamente dito, o sentido está também relacionado com as linguagens e símbolos discursivos. Então é

34 Esse diálogo é proposto por BURKE, Peter. História e teoria social. São Paulo: Editora da UNESP, 2002. 
através da linguagem que uma mensagem pode ou não ser decodificada numa espécie de sentimento de cumplicidade simbólica ou de radical rejeição. Estabelece-se uma relação de fascínio e temor. Nesta perspectiva, a história, além de ser um bem cultural inestimável, com valores implícitos e explícitos, é uma forma de comunicação entre o passado e o presente, entre as idéias de futuro que se tinha no passado e a possibilidade de cultura da mudança do tempo presente, tendo como fio condutor os sentidos.

Parece-nos que está aí a importância dos nossos demônios tutelares que nos acompanham culturalmente e a suspeita sobre o fato de procurarmos constantemente o sentido e o significado do conhecimento histórico. Então, também, aquilo que por vários séculos de ciência formal foi denominado de irracional através da falácia da representação da realidade pode agora contribuir para uma cultura da mudança. Pois, a história é uma textura de representações do passado e não uma ciência com corpo de proposições gerais que expressam somente fatos descobertos. A história nessa configuração é muito mais uma 'invenção controlada' do passado do que a possibilidade de apreensão da realidade materializada.

Falar sobre desejos na atualidade do tempo presente significa discutir, na visão do senso comum, sobre algo desconhecido, escondido e excluído ou não dito. Desejos não seriam materialmente capturados por sua condição específica. Eles existem, isto sim, como indícios de possibilidades quando os relacionamos aos sonhos, fantasias, mitos, histórias infantis ou mesmo a perversão sexual, loucura individual e catástrofes individuais, podendo eles ser empíricos ou transcendentais.

Nesse sentido, a tentativa de buscar uma outra realidade do desejo precisa contar com as noções e mecanismos da exclusão, do escondido e da destruição, as quais moldaram a constituição da sociedade burguesa com sua objetividade e subjetividade individual, mas que, sobretudo, abriram flancos para a divisão entre as noções de objetividade e de subjetividade.

Um mecanismo central da exclusão, relacionado com as posturas advindas do iluminismo está vinculado à concepção do que seria irracionalidade, a qual compõe de certa forma a estrutura do discurso moderno. Com este aspecto, que sem dúvida deu os parâmetros da ciência moderna e as forma de discurso, estabeleceu-se o contato e a garantia de manutenção e continuidade sobre o fim do desejo e a perpetuação da mentalidade científica.

Nesse sentido, a separação entre o emocional e a racional, que em nenhum outro momento esteve tão aguda, levou a uma postura (anti) lógica por um lado e a busca de uma lógica formal do outro, a qual orientou a esquematização do domínio e da exploração do emocional para que as posturas humanas fossem meramente agentes funcionais de uma prática teórica. Uma postura, que diluísse as fronteiras ainda existentes entre desejo e ciência, seria possível apenas a partir de uma rede na qual o valor 
fosse o aspecto central. Por isso mesmo é difícil distinguir os critérios de estabelecimento daquilo que seria ou não um problema relevante.

Tal aspecto tornou-se uma constelação fundamental desde o iluminismo, pois a tarefa da crítica fora sucumbida pela razão instrumental. Através do processo de privatização do irracional, o que significa a perspectiva, o sentimento, o desejo, abateu-se sobre este aspecto a capacidade de esvaziamento daquilo que ela não se conseguia explicar.

No lugar de uma explicação lógica, criou-se um novo mito, que se situa naquela fissura na qual cabiam todos os demais aspectos impossíveis de ser captados pelas técnicas heurísticas. E é, exatamente, neste mito que aparecem aquelas forças anônimas orientadoras do pensamento e de ações humanas, as quais a crítica iluminista deixou em suspenso. Um caminho alternativo não é possível lá onde se procurou uma postura contra-iluminista, pois também naquele aspecto estava já delineada uma auto/representação conceitual do 'irracional'.

Nesse sentido seria necessário, em primeiro lugar, aventar a possibilidade de perceber o destino do mito do iluminismo na cultura contemporânea para que a partir de então se pudesse proceder a uma crítica da lógica. Aliás, uma crítica da lógica somente é possível sendo lógica. Todo resto deixa tudo como está. Quem sabe apresentamos alguns indícios daquilo que estamos referindo.

Fantasias e sensibilidades são noções do desejo nas quais o irracional conseguiu se manter por mais tempo. Antes do iluminismo e enquanto uma filosofia crítica se constituiu como necessária ao mundo moderno, a fantasia e a sensibilidade são exatamente os princípios que mais claramente aparecem no discurso público.

Por outro lado, estas noções marcam para a sociedade burguesa uma (auto)identificação como alternativa à razão dominante: o artista e o homem da sensibilidade, quase sempre foram captados e representados em uma única figura, mas também foram entendidos com a contra imagem permitida ante ao processo de automação do progresso tecnológico. O resultado desta crítica viria constituir-se numa espécie de consciência pesada ou resto cultural fragmentado do passado.

Com este fragmento cultural, a fantasia e a sensibilidade receberam a tarefa de carregar o desejo proibido, o qual diferenciava a sociedade burguesa daquela anterior ao iluminismo. Assim, o 'ruído do sensível', a 'saudade do desejável' e a 'mudança das imagens', entre outras expressões, formam uma corrente dentro do desejo primeiramente apreendidas como sendo o 'mal', mas que em seguida passam a alimentar o grande público como sendo o fascinante e, finalmente, para legitimar a consolidação da razão industrial, na qual cada vez mais o preenchimento de desejos adquire um ritual de liberação das energias de fragmentos culturais. 
Em outras palavras, a atribuição de valores ao sujeito adquire conotações e relações de objetividade. Em meio disso no tempo presente a publicidade do privado através da reificação da pornografia em som e imagem restabelece uma perspectiva do contexto arcaico do desejo, na qual pode ser feita a leitura de uma lógica formal da abstração. Isto significa que a natureza interior do homem é apresentada como a natureza exterior, porém sob o poder ritualizado do banal. ${ }^{35}$

Também a sexualidade recebe a forma vulgarizada da natureza onde um corpo sem espírito é subsumido por um espírito sem corpo para que possa exprimir mais valor de mercado. Nesse sentido, a fantasia fora, na pré-história da subjetividade, a garantia materializada da perspectiva de valor contrária à abstração absoluta. Mesmo assim, não devemos partir de uma corrupção histórica dos desejos em termos de fantasia, pois isto nos levaria a uma distorção na compreensão da própria humanidade.

A incerteza sobre a constituição dos sentimentos e desejos somente pode ser apreendida como o resultado dentro de um longo processo civilizador, o qual está fundamentado numa espécie de pré-consciência dos desejos, que a partir de certo momento em diante gera a substância para a alienação (da qual ele próprio se alimenta).

A conseqüência mais evidente da reificação dos desejos é uma catástrofe emocional profunda, a qual talvez ainda não pode ser explicitada em termos de seus resultados históricos e culturais. O significativo aumento de internações em casa de tratamento psiquiátrico, o aumento de suicídios de crianças e adolescentes ou ainda as mais variadas formas de agressões podem indicar as marcas de algo (in)transparente, porém complexo e latente na sociedade contemporânea. ${ }^{36}$

Os parâmetros da racionalidade dos fins, orientadores da sociedade burguesa, falharam completamente ante a necessidade da ação prática na organização dos fundamentos na sociedade moderna. As motivações sociais ao nível do trabalho social não funcionam apenas pela lógica econômica, mas, apesar dela e por ela, por que teria sido praticada uma visão de mundo emocional, na qual estavam presentes os elementos que as ciências humanas gradativamente foram perdendo através da sedimentação da racionalidade dos fins.

O alargamento dos princípios econômicos também seguiu um esquema, que pode ser identificado da seguinte forma: através do processo de distorção dos verdadeiros fundamentos, a lógica da abstração pode se

35 Ver estes vínculos em SARTORI, Giovanni. Homo videns. Televisão e pós-pensamento. Bauru: Edusc, 2001.

36 Talvez fosse uma empreitada interessante relacionar tal aspecto com aquilo que seria a história do medo. Um trabalho circunstanciado foi feito por DELUMEAU, Jean. História do medo no ocidente - 1300-1800. São Paulo: Companhia das Letras, 1996. 
colocar como agente explicativo naqueles casos em que ocorre a destruição e a desertificação das motivações críticas. ${ }^{37}$

Tal explicação por vezes ainda é aceita especialmente dentre aqueles seguidores de certas críticas ortodoxas e teóricas contrários a uma ampliação do horizonte fenomenológico. Outrossim, observa-se que cada vez mais aparecem os sintomas do paradoxo que apontam claramente sobre os custos da emancipação social e sobre a incompetência profunda de compreensão dos campos e instâncias das ações.

Nesse caso, os movimentos verificados durante os anos da década de 1960 já mostraram a fragilidade de uma razão transparente e pública. Fora também nestes movimentos que se preparara o caminho para afirmar o desconhecimento dos pedagogos em relação à educação, os economistas apenas como especialistas de crises, os historiadores apenas como conhecedores do passado etc.

Estes paradoxos nos campos de especialistas correspondem ao domínio da expertocracia, que são incapazes de compreender orientações de desejos individuais e coletivos. A desconfiança e a insegurança dos homens em relação a si mesmo levam a paralisia quanto às perspectivas orientadoras de futuro. Portanto, a catástrofe emocional está representada, por um lado, na perda da sociabilidade e, por outro, no aprisionamento do privado em uma cela sem grades. Por isso, muitos buscam uma saída na aceitação da existência de uma razão pré-moderna, na qual ainda não haveria uma delimitação pontual entre o sujeito e o objeto e, muito menos, de uma racionalidade dos fins.

Na medida em que esta delimitação se estabelece como parâmetro da sociedade moderna através da objetivação da realidade, homens se tornos estranhos a si mesmos e aos outros. A garantia de uma natureza interna, própria da sociedade tradicional, fora perdida e como ela também a relação consciente com a própria natureza.

O que resta é uma configuração estranha que internalizada se torna incapaz de sustentar qualquer perspectiva de solidariedade em quaisquer classes da sociedade contemporânea. Preso em uma terminologia científica está cada indivíduo multifacetado e vazio, incapaz de perceber seus limites bem como suas possibilidades. Ao mesmo tempo, as relações com outros indivíduos provenientes da necessidade de convivência pacífica, passam a ser ditadas pela ordem impessoal do mercada que, por sua vez, diz o que e quais são as necessidades.

Será que não poderíamos encontrar, no entulho do desenvolvimento da sociedade moderna, constelações de desejos que apontassem desde séculos para a produção de trabalhadores sem desejos, que por assim

37 Ver especialmente a tese de Max Weber em sua Sociologia das religiões. Especificamos isto ao nível cultural no terceiro item deste texto. 
dizer sinalizam sobre as dificuldades e, por vezes, explicaria o fracasso dessa produção?

Claro que este questionamento contém imprecisões, pois isto poderia sinalizar respostas no espaço da religião católica com sua desestruturação do campo dos desejos delimitados pela loucura e na perspectiva da ética protestante, a qual se aproxima do princípio valorativo da abstração real ${ }^{38}$. Porém, mesmo nestes dois espaços é possível perceber o estabelecimento orientado para a fantasia e para a sensibilidade.

Este direcionamento orientado levou e gerou a crise religiosa institucional, que talvez seja a crise mais radical de todas as conhecidas na história ocidental e não raramente oriunda de hereges e ateístas. Se então os desejos passam a ser revividos na atualidade, a crise das igrejas institucionais se explicaria exatamente pela falta de desejos motivadores.

O juramento a Deus foi assegurado através de um determinado discurso e isso ocorreu não através dos inimigos da igreja, mas sim pela prudência de todos aqueles que buscam lá o subsídio religioso. Assim, os pecadores, hereges, ateístas e outros mais foram aqueles que serviram como pretexto de manutenção e endurecimento da ordem. A religião não está aí para os opositores a ela, mas para os seguidores. Entretanto, são os opositores que moldam o regramento dos desejos.

Este é o aspecto externo que os seguidores mal conseguem perceber. Visto de fora, aos poucos vai ficando mais claro, qual a força extraordinária que estava aprisionada nas religiões ocidentais antes mesmo dela se institucionalizar e passar a existir em função de sua institucionalização. ${ }^{39}$

Parece-nos, exatamente, neste ponto o espaço para encontrarmos elementos de uma arqueologia da subjetividade, pois bastaria que nos lembrássemos dos mosteiros e igrejas, das cruzadas e dos processos inquisitoriais contra bruxas e feiticeiras, que podem ser descritas como o desastre do sem desejo, cuja moral e ética conheciam apenas o sim e o não, tal qual ao funcionamento de um programa de computador. Portanto, a religião já não teria mais nada a oferecer em termos de orientação para a convivência no mundo contemporâneo.

Uma das primeiras terapias para a esquizofrenia, com fundamentos psicanalíticos, é aquela compreendida como de 'preenchimento' de desejos simbólicos. As novas contribuições para a história da loucura na época da razão poderiam esclarecer que no processo de constituição da sociedade moderna os desejos foram excluídos como sendo eles o específico, ao mesmo tempo em que surgiria uma nova espécie de loucura.

38 Discutimos este aspecto sob o prisma da cultura em Max Weber, conforme DIEHL, Astor Antônio. Max Weber e a história. $2^{a}$ edição. Passo Fundo: UPF editora, 2004, cap. 3.

39 Ver LEITES, Edmund. A consciência puritana e a sexualidade moderna. São Paulo: editora Brasiliense, 1987. 
Trabalhos mais recentes sobre a teoria e terapia das psicoses levantam a suspeita que a normalidade burguesa (que pode ser percebido como resultado infinito de um processo de violência) na esquizofrenia como num espelho pode apresentar verdades desde que haja a técnica instrumental para tal leitura. A relação entre capitalismo e esquizofrenia constitui-se, no processo de socialização da sociedade moderna e ela pode significar a reação da natureza humana, como uma chave para abrir possibilidades alternativas de compreensão de ações no passado.

Por certo, tudo isso seria um tiro pela culatra se percebêssemos apenas na esquizofrenia a solução para a charada da socialização moderna. A socialização é vítima do processo, um objeto de experimentação, um lugar para a doença e um espelho para projeções exclusivas. Mas é exatamente este o espaço do estar excluído do mundo através do erro daquele que pode se manter o mais fiel possível aos seus desejos. ${ }^{40}$ Melhor ainda no sonho que vai sendo desvirtuado com o desenvolvimento, pois nele está contida a loucura da lógica dos desejos desde as delimitações arcaicas até a presença dos poderes institucionalizados, porém micrológicos.

É possível perceber na engenharia das metáforas a base da experiência esquizofrênica e a partir daí a produção do desejo como uma interpretação mecanicista do mundo. Se tal interpretação leva a alguma referência, eu não saberia afirmar, mas em todo caso podemos observar na loucura o somatório das mais diferentes ordens de desejos, o que pode, imediatamente, significar que os desejos somente são passíveis de reconstituição pelo alto preço de sua normatização do sentido e da racionalização dos desejos. ${ }^{41}$

Nas posturas tradicionais dos processos de socialização não se fazia necessário perceber o desenvolvimento humano em constante relacionamento com o seu todo, mas sim aparecia tal desenvolvimento concebido a partir da exclusão e do sofrimento.

Portanto, a importância não seria atribuída pela verificação do processo de transformação relacionado à natureza na constituição das necessidades e das atividades conscientes, como forma de sobrevivência, mas sim apenas pela possibilidade de uma resposta plausível da mudança em si, como se fosse a mudança de um espaço para outro, não importando as múltiplas relações possíveis.

Neste sentido, valeria não a necessidade com sua racionalidade dos fins na constituição da história da natureza humana, mas sim agora cada desejo transcendente da lógica do desejo. Pois, uma submissão de desejos sob um fim estranho ao desejo é por isso impossível.

40 Conforme PHILIPS, Frank. Op. cit.

41 Este aspecto está relacionado com o processo de secularização, conforme o livro de MARRAMAO, Giacomo. Poder e secularização: as categorias do tempo. São Paulo: Editora da Universidade Estadual Paulista, 1995. 
Este aspecto só possui sentido, se desejos forem transformados em necessidades. Somente neste caso é possível perceber uma caracterização econômica quando se passa a viver da estilização dos fins de desejos na esfera da sobrevivência. O desejo já precisa estar fixado no necessário antes mesmo dele servir como instrumento racional da organização social. Assim mesmo, cada um dos aspectos componentes desta racionalização precisa se impor culturalmente com suas potencialidades de poder.

Trata-se aqui de um processo concorrente de aspectos que precisam se impor, o que em outras palavras significa um processo de homogeneização dos diferentes elementos em disputa na cena social, que, em conseqüência, sempre terá vítimas na medida em que o específico é submetido ao geral. Assim, aquilo que fora específico só poderá se fazer realidade se vencedor no conflito entre os diferentes, passando a ser a generalidade.

Em outras palavras, pode-se traduzir este processo através do embate entre as diferentes subjetividades que ao impor-se no processo de racionalização evidenciam, como resultado final, a predominância da objetividade. Tal predominância da objetividade pode facilmente enveredar para uma ordem mitológica do processo de desenvolvimento humano e social, cuja caracterização não se distancia muito dos esquemas apresentados nas utopias.

A reconstrução de uma ordem do desejo é uma possibilidade simbólica da própria ordem, na qual a fantasia e a razão fazem parte. Ela é uma ordem da linguagem e uma experiência de vida instalada nas estruturas representadas. Nesse sentido, os desejos são colocados naquela ordem por um princípio da violência.

Então, a socialização humana é impossível de ser percebida sem o potencial de tornar o desejo uma vítima. A ordem simbólica dos desejos reage sob uma fraqueza inerente a ela. O desejo como o preenchimento da ordem já está diluído antes mesmo da ordem se impor como objetividade. Nela o desejo será assegurado como algo que lhe falte, resultando disso a possibilidade de garantia das regras, as quais podem assegurar por séculos os próprios processos de socialização.

Nesse caso específico, o regramento disciplinar pode ser identificado com a estrutura da imaginação social que traz para o presente os limites e as possibilidades humanas da transgressão. De fato, a ordem simbólica será assegurada através da centralidade ocupada pela fantasia, que pelas suas características será sempre mais individual do que coletiva. Neste ponto poder-se-ia trazer para o debate duas estruturas da ordem dos desejos, a qual pode ser histórica e biográfica.

Um discurso sobre o desejo pode agregar o mito do iluminismo, especialmente, por duas razões: o poder e a abstração. Este poder tornou-se a segunda natureza tanto na prática como na teoria, a qual passou a determinar os modos de pensar e agir na sociedade moderna. Por isso, torna-se 
importante que um discurso sobre o desejo tenha em vista a ritualização de autosuficiência da lógica binária dos discursos dominados pela razão. Este aspecto impõe-se, inicialmente, através dos conceitos científicos e do senso comum com os quais a outra realidade dos desejos é excluída ou escondida. ${ }^{42}$

A separação feita pela tradição filosófica, e reforçado pelas ciências humanas através do processo de divisão do trabalho esqueceu por muito tempo que os seus fundamentos estavam assentados e formaram um mito, ou seja, que ela seria constituída por um discurso não esclarecido. Somente com o debate realizado durante o século XIX, os cientistas passam a se preocupar com o caráter de seu discurso, com o caráter experimental e com o caráter modelar de suas disciplinas. ${ }^{43}$

Tal preocupação no desenvolvimento da vocação científica significa uma espécie de segundo iluminismo pelas profundas mudanças causadas nas epistemologias de suas disciplinas. Também na linguagem cotidiana, onde o desejo passou a configurar de forma limitada e diminuída do seu significado mais profundo, ele passou a fazer parte de cartões de felicitações, desejo de boas festas, de ano novo etc. Apesar deste senso de simplificação, seu uso é passível de significados sobre outras realidades se forem colocados nos processos e esferas de produção, distribuição e circulação de sentidos. ${ }^{44}$ Talvez por isso, os desejos jamais poderão ser destruídos em sua essência.

Por outro lado, poderão ser destruídas suas ordens e suas estruturas simbólicas que serão recompostos em novos significados, produzindo diferentes hierarquias e poderes. Nesta perspectiva, desejo contém em si a ordem e a revolução, a estabilidade e a desordem, a organização institucional e a sua dissolução. Portanto, a compreensão do desejo não se dará através da sistematização, da identificação e universalização, mas sim através da fragmentação, diferenciação do conhecimento. Somente assim, a ordem simbólica pode ser compreendida na sua estrutura profunda.

Um discurso sobre desejos não pode ser anônimo: ele precisa fundamentar uma nova relação entre o geral e o específico. Somente então, conseguir-se-á preservar o geral do seu vazio e o específico de ser apenas um caso. Com o surgimento da sociedade moderna, especialmente, a partir do iluminismo gradativamente foi sendo privatizada a relação da burguesia ante a morte. Os medos perante a morte e da finitude humana não puderam ser superados, porém escondidos atrás de palavras majestosas, discursos bem articulados e mesmo conceitos. Discursos ante a morte ou do amor

\footnotetext{
42 VENTURI, Franco. Utopia e reforma no iluminismo. Bauru: Edusc, 2003.

43 Conforme a argumentação de VOGT, Rolf. Psychoanalyse zwischen Mythos und Aufklärung oder Das Rätsel der Sphinx. Frankfurt: Fischer, 1989.

44 GUMBRECHT, Hans Ulrich. Modernização dos sentidos. São Paulo: Editora 34, 1998.
} 
trazem consigo, em vez disso, os rastros de uma estratégia de exclusão. Em especial, isto é verificável com as noções científicas, como na medicina, na antropologia, na pedagogia entre outras, nas quais estão contidos os limites de expressões reveladoras do estranhamento da natureza.

A constituição e o desenvolvimento da ciência dentro deste paradigma talvez seja um exemplo da precariedade de pesquisas e estudos sobre a paz e a guerra, sobre questões ecológicas e destruição da natureza, que, em última instância, são vítimas da razão instrumental. Está claro que tais estudos não são soluções aos problemas estruturais, mas podem significar o despertar de uma razão capaz de possibilitar chances alternativas aos discursos racionalistas.

Neste sentido, parece-nos que as justificativas levantadas acima dãonos a dimensão da complexidade quanto à subjetividade amarrada ao desejo. Tal complexidade aumenta ainda mais quando a conectamos com as possibilidades que se abrem para a história ante a tentativa de compreensão das questões do tempo presente dentro de uma ótica da cultura da mudança.

\section{Cultura historiográfica da mudança}

Neste item pretendemos discutir o processo de produção do conhecimento histórico e as possíveis tarefas da cultura historiográfica na perspectiva da tradição e da inovação. Nesse sentido, tomamos como base à noção de cultura historiográfica. Entendemos por cultura historiográfica um conjunto de cinco matrizes com seus respectivos elementos interligados.

A primeira matriz tem sua origem no debate proposto por Thomas Kuhn, com a publicação do livro A estrutura das revoluções científicas, em 1962. Kuhn apresenta um debate sobre a noção de paradigma, as conseqüências para a ciência quando ocorre a chamada mudança paradigmática e os fatores agentes dessa mudança.

O debate desencadeado por Kuhn foi assimilado com diferentes graus de recepção na história. Jörn Rüsen então propôs uma matriz disciplinar para a história como modelo para a discussão teórico-epistemológica. A matriz formulada por Rüsen é composta por cinco elementos: os interesses pelo conhecimento sobre o passado; as perspectivas teóricas que orientam a pesquisa; as metodologias, as técnicas de pesquisa e as diferentes fontes; as formas de representação do passado através das narrativas e, finalmente, as funções didáticas dos conhecimentos histórico no contexto sociocultural. ${ }^{45}$

45 DIEHL, Astor Antônio. A cultura historiográfica e inserção hermenêutica. Narrativa e controle da tragicidade na história. In: Rev. História: debates e tendências. Passo Fundo: Mestrado em História/CPH/RS, v. 02, n 01, 2001. p. 33-52. 
A segunda matriz tem seu foco centralizado nas formas de recepção dos debates teóricos na comunidade científica na própria história e demais ciências humano-sociais. Essas formas de recepção são constituídas de três vetores: a ortodoxa, a adaptada e a crítica. ${ }^{46}$

A terceira matriz tem seu esforço concentrado sobre as experiências historiográficas refletidas sobre a modernidade e ela e composta pelas nações modernização, modernidade e modernismo.

A quarta matriz apresenta as experiências historiográficas sobre a pós-modernidade e ela é composta pelo debate sobre a tensão entre modernidade - pós-modernidade e as repercussões dessa tensão na disciplina história.

E, finalmente, a quinta matriz representa o estético-narrativo da história e ela é constituída a partir do debate em torno do texto histórico-historiográfico e as respectivas representações de estruturas e de sujeitos.

Com esse primeiro entendimento sobre a noção cultura historiográfica podemos seguir adiante, dizendo que por processo de produção do conhecimento histórico compreendemos um conjunto de práticas desenvolvidas tanto em nível acadêmico como não acadêmico.

Esse conjunto de práticas acadêmicas inclui a elaboração do projeto, a revisão da literatura (teórica e temática), o levantamento de fontes e dados, a redação do texto e sua publicação. Portanto, em nossa avaliação só poderão estar presentes os textos efetivamente públicos e de acesso, assegurado.

Observa-se, ultimamente, um amplo processo de produção de dissertações e teses no contexto dos programas de pós-graduação e com isso, a socialização da pesquisa dos membros da comunidade de historiadores. Com esse aspecto não queremos afirmar que a socialização dos conhecimentos produzidos ocorra, necessariamente, com igual intensidade no contexto mais amplo da sociedade através da publicação de livros e artigos de acesso geral.

Nesse sentido, trata-se de verificar a hipótese segundo a qual, apesar do anúncio da crescente burocratização, leia-se especialização da história, o processo de produção continua sendo predominantemente artesanal. Conseqüentemente, a socialização do conhecimento pelos membros da comunidade científica na pesquisa está sendo definida pela performance individual e singular do historiador.

Observa-se, também, a crescente institucionalização e consolidação de cursos de pós-graduação num processo que poderíamos denominar de interiorização do conhecimento.

46 Discutimos essa matriz em DIEHL, Astor Antônio. A cultura histórica brasileira. Porto Alegre: Edipucrs, 1993 especialmente p. 26-27. 
Além das questões institucionais e quantitativas da produção do conhecimento devemos considerar a ciência e a atividade científica como eminentemente sociais. A história da ciência histórica se interessa pelos próprios cientistas em suas condições de trabalho.

Nesse sentido, existem várias alternativas conceituais para o estudo do processo de produção do conhecimento histórico. Entre estas alternativas destacamos: o conceito de comunidade científica, introduzido por Polany, presente em Merton e desenvolvido por Kuhn, ${ }^{47}$ o conceito de ethos científico de Merton; o conceito de campo científico e habitus de Bourdieu, ${ }^{48}$ bem como o de habitus na perspectiva de Norbert Elias.

A partir dos anos 1970 e 1980, com a criação dos programas de pósgraduação, entramos numa fase da cultura historiográfica que é caracterizada pela crise dos parâmetros científicos tradicionais e pela diversidade de histórias, porém fortemente institucionalizada nas universidades. Nessa fase assistimos, além da interiorização da produção do conhecimento e sua correspondente profissionalização, a emergência de alternativas temáticas e teóricas. ${ }^{49}$

A primeira tendência lembra uma orientação mertoniana, na qual ocorre a dissociação entre ciência e vida pública. Desenvolve-se uma historiografia sob a jurisdição de uma comunidade científica orientada por um ethos específico. Através desse ethos específico e autônomo, procurou-se atingir os fins próprios da lógica científica. Nessa tendência, a historiografia não deveria servir ao Estado, ao mercado, nem a quaisquer outros sujeitos sociais.

A segunda tendência prevê o locus departamental, como sendo uma espécie de autor para a construção de redes em torno de objetos definidos pela vocação solving problems, estimulando-se, para tanto, a criação de laboratórios, arquivos e implementando linhas de pesquisa e áreas de concentração.

A terceira tendência consiste numa forte influência francesa na cultura historiográfica pela qual ocorre a recepção maciça e uma aproximação da nova história francesa com a história cultural, fazendo da história uma forma medial de comunicação entre passado e presente. Evidente está que a história nova gerou uma revolução na historiografia, como muito bem menciona Peter Burke. ${ }^{50}$ Mas, sua forte tendência ao mercado medial acentuou a sua patologia. Refiro-me a patologia do esgotamento e a sua perda de sentido em termos de busca dos parâmetros modernos de ciência.

47 KUHN, Thomas. Op. cit.

48 BOURDIEU, P. A economia das trocas lingüísticas. São Paulo: Edusp, 1996; Razões práticas: sobre a teoria da ação. Campinas: Papirus, 1996. BOURDIEU, P. Campo intelectual e projeto criador. Problemas do estruturalismo. Rio de Janeiro: Jorge Zahar, 1986.

49 Fizemos isso em Cultura historiográfica brasileira nos anos 80. Porto Alegre: Evangraf, 1993 (2ª edição é da UPF, 2004)

50 BURKE, Peter. A Escola dos Annales (1929 - 1989). $2^{\circ}$ ed. São Paulo: ed. da Unesp, 1991 
De forma geral podemos afirmar que apesar das três tendências identificadas isoladamente, elas ocorrem simultaneamente, mostrando-nos, sobretudo, que não há mais um conhecimento estabelecido de verdades absolutas e últimas. Por mais paradoxal que possa parecer, a história está em franca popularização, e cada vez mais ela vem ocupando espaços nos diferentes meios de comunicação. Cada vez mais, a legitimidade da história centra-se na pluralidade e na multiplicidade, no imediato e no tempo presente, causando a sedução do leitor através de uma narrativa aberta sem os dogmatismos de pensamento do século XIX.

Por outro lado, assistimos um avanço numérico considerável na produção de histórias municipais, locais, regionais e personalizadas. São cada vez mais produções em micro escala, que buscam a afirmação dos saberes locais, das identidades étnico-culturais e de posturas político-administrativo-municipais. Uma parcela considerável desses textos é produzida fora dos parâmetros universitários e, portanto, do controle da comunidade científica.

Apesar da inovação metodológica e temática da história, não podemos deixar de mencionar a fugacidade do texto histórico e sua configuração teórica, provocada pelo afronto à tradicional razão histórica. Nos anos da década de 1980 e 1990, a cultura historiográfica brasileira vem desenvolvendo-se num intenso debate em torno dos problemas apontados pela pós-modernidade. As clivagens desse debate localizam-se em parte sobre a crítica da idéia de progresso, da razão histórica e do próprio sentido do conhecimento histórico, as quais foram as molas mestras das perspectivas de modernidade.

Por outro lado, as soluções micro e culturais são também uma resposta ao processo de globalização em forma de resistência, de identidades e de culturas locais. Assim, os critérios de fundamentação moderna e validade da história ciência estão hoje sob suspeita. ${ }^{51}$

Nessa constelação ampla existem dois parâmetros básicos que devemos considerar em relação à cultura historiográfica: (a) a formação da atividade científica na comunidade e (b) a estrutura e concepções na produção do conhecimento histórico. ${ }^{52}$

Frente a essa tese, a hipótese plausível nesse contexto é a da constante busca de parâmetros que possam configurar a performance da ciência histórica. Um desses parâmetros é o estabelecimento de elementos capazes de estimular premissas para um programa mínimo, mesmo que precário

51 Em termos epistemológicos procuramos discutir isso no confronto entre os paradigmas modernos e pós-modernos em DIEHL, Astor Antônio; TEDESCO, João Carlos. Epistemologias das ciências sociais. Considerações introdutórias de um debate. Passo Fundo: Clio Livros, 2001.

52 Os dois aspectos apontados não serão discutir aqui. Entretanto, seria por demais, interessante vincula-los na relação específica com os programas de pós-graduações e a questão das regionalidades. 
para a disciplina. Tais premissas constituem-se em meta-discurso, que consigam abranger as mais diferentes representações localizadas.

Tal meta-discurso deverá dar conta dos elementos discursivos anárquicos, que querem romper com o personalismo historiográfico existente, e aqueles cujo objetivo é a configuração da disciplina histórica. A dificuldade está exatamente nesse ponto, que é o xis nevrálgico da questão. Por outro lado, a constituição dos elementos dessa meta-discurso poderia estar historicizada, pois o diálogo irá apresentar experiências disciplinadoras e impulsos emancipatórios. ${ }^{53}$

Portanto, um primeiro aspecto é a necessária (re)configuração entre o discurso teórico e a razão prática, entre o pensar representativo do mundo e a vivência da experiência daqueles que objetivamos reconstruir num processo de atualização do passado.

A contemporaneidade do não-contemporâneo implica em exercícios sócio-culturais de interesses pelo conhecimento histórico. Tais interesses independentes do contexto revelam a capacidade do sujeito cognitivo consciente, reconstruído através das práticas existenciais e do conjunto de tendências do paradigma dominante. Esse aspecto por si só já gera um conflito, estabelecido entre o existencial do historiador e o paradigmático de sua ciência.

Nesse aspecto, não devemos confundir as práticas existenciais nãodiscursivas como, por exemplo, comportamento cotidiano, com discursos impressos sobre o cotidiano. Ou seja, a orientação de misturar experiências existenciais e textos de crítica historiográfica. Aliás, essa orientação faz parte da patologia da história como ciência. Portanto, o foco central desse primeiro elemento é o da história como experiência ou espaço das experiências.

O segundo elemento da meta-discurso é o das perspectivas orientadoras sobre o passado, ou seja, o conjunto de teorias, as quais dão significado ao passado. É através das perspectivas orientadoras que os interesses ajudam a compreender as transformações temporais do homem, do seu mundo e a consciência de seu reconhecimento como histórico.

O terceiro aspecto constitutivo da meta-discurso é as orientações e regras metodológicas, com as quais as experiências do passado são inseridas nas perspectivas orientadoras através da pesquisa e de todo arsenal técnico de manuseio documental na significação das informações. A inserção das experiências do passado nas perspectivas orientadoras é feita através das estratégias de pesquisa. $\mathrm{O}$ arsenal técnico e as estratégias vão mudando conforme as orientações teóricas.

O quarto elemento é constituído pelas formas de representação historiográfica, através das quais são elaborados os textos e discursos sobre

53 Ver mais em DIEHL, Astor Antônio. Cultura historiográfica: memória, identidade e representação. Bauru: Edusc, 2002. 
o passado. A dimensão textual-discursiva compreende aspectos como memória, continuidade/ruptura, comunicação, identidade e sentido do tempo, vinculados a quatro estruturas narrativas: a exemplar, a tradicional, a crítica e a genética. ${ }^{54}$

E, finalmente, o quinto elemento constitutivo da meta-discurso envolve as funções do conhecimento histórico no contexto social e individual. Em outras palavras, essas são as funções didáticas do saber histórico, através das quais germinam novos interesses sobre as práticas sócio-culturais. Exatamente nesse aspecto está presente a profunda vinculação entre presente e o passado. Nesta perspectiva podemos afirmar que as funções do conhecimento histórico não estão no fato e na garantia de esboçar o futuro como algo que estaria além de nosso tempo, mas sim compreender as idéias de futuro que se tinha no passado. Tal compreensão está assentada nas expectativas de produzirmos representações e, por que não dizer, invenções controladas do passado que tenham um arsenal utópico.

Portanto, entendemos que a performance da história como disciplina com plausibilidade passa necessariamente pelo estabelecimento desses cinco elementos constitutivos como um programa epistemológico mínimo. Independente da postura teórica, esse meta-discurso possibilita, sobretudo, uma concepção da própria possibilidade histórica e do seu desenvolvimento.

Não seria exagerado afirmar aqui, para finalizar, que a própria busca desse acordo é também repleto de produtividade para o pensamento historiográfico, pois a relação dialógica é a maneira pela qual se revela a consciência da produtividade. Sem dúvida, o aparecimento da consciência histórica, no sentido da tomada de posição, configura o aspecto mais importante de constituição da história como disciplina moderna e este é o parâmetro de compreensão fundamental da historicidade do passado, bem como evidencia o reconhecimento intelectual contemporâneo. A época é das reconstituições de memórias individuais, coletivas e, conseqüentemente, essa perspectiva exige do historiador (também como leitor) uma posição quanto às infinitas leituras possíveis do passado a partir dos diversos sistemas de referência. Esse é o momento de revigoramento cultural e de inserção da hermenêutica na compreensão do passado, rompendo dessa forma com o exclusivismo de uma verdade científica.

Essa eterna procura daquilo que não pode ser totalmente encontrado levou a Max Weber, por exemplo, a seguinte interrogação: por que motivo, então, nos entregamos à tarefa que jamais encontra fim e não pode encontra-lo? Talvez, poder-se-ia ainda agregar a posição de Goethe quando afirma: precisaria isto ser assim, logo aquilo que traz a felicidade do ho-

54 Estas estruturas narrativas da história foram desenvolvidas por Jörn Rüsen. Procuramos operacionalizá-las em DIEHL, Astor Antônio. Do método histórico. $2^{\mathrm{a}}$ edição. Passo Fundo: UPF editora, 2001. 


\section{Astor Antônio Diehl}

mem ser de novo fonte de sua miséria. Não precisamos necessariamente concordar com ambos, mas a pergunta ainda continua sendo existencial: para que tudo isso se não é para podermos ter alguns momentos de felicidade. 